Check for updates

Cite this: Chem. Sci., 2019, 10, 6519

๑ All publication charges for this article have been paid for by the Royal Society of Chemistry

Received 23rd November 2018 Accepted 21st May 2019

DOI: $10.1039 / \mathrm{c} 8 \mathrm{sc05230a}$

rsc.li/chemical-science

\section{A highly active non-precious transition metal catalyst for the hydrogenation of carbon dioxide to formates $\uparrow$}

\author{
Benjamin G. Schieweck, Niklas F. Westhues (D) and Jürgen Klankermayer (D) *
}

Herein a highly active non-precious transition metal catalyst system for homogeneous hydrogenation of carbon dioxide to formate is presented. The application of selected nickel(॥) salts in combination with tailored multidentate ligands enabled the effective transformation of carbon dioxide with an exceptional TON of up to $4.65 \times 10^{6}$. This unprecedented productivity based on the novel nickel catalyst not only outmatches that of existing systems containing first row transition metals, but also established catalysts based on precious transition metals.
The utilization of carbon dioxide $\left(\mathrm{CO}_{2}\right)$ as versatile chemical feedstock has fascinated chemists for decades, but only very recently have important developments in molecular catalysis paved the way towards the creation of novel chemical processes using this important resource. ${ }^{1-3}$ Especially, the reduction of $\mathrm{CO}_{2}$ with molecular hydrogen has been investigated in great detail in the last few years and effective catalysts for the synthesis of formic acid, dimethoxymethane and methanol could be developed. ${ }^{4-9}$ In 1935, Farlow and Adkins had already discovered the formation of formates from $\mathrm{H}_{2}$ and $\mathrm{CO}_{2}$ using a heterogeneous RANEY®-nickel catalyst in the presence of amines. ${ }^{10}$ Later, $\mathrm{CO}_{2}$ hydrogenation to formic acid was reported by Inoue et al. in 1976 for the first time with a molecular catalyst, and platinum group transition metal complexes modified with mono- and bisphosphine ligands proved to be especially effective. ${ }^{11}$ As the hydrogenation of $\mathrm{CO}_{2}$ to formic acid is endergonic, a stabilizing agent, a base or a Lewis basic solvent, is needed to actually yield formates instead of free formic acid. . $^{212}$

Based on this important development, precious metal catalysts achieving TONs of up to several million moles of formate per metal centre could be obtained. In this transformation, molecular iridium and ruthenium catalysts showed by far the highest activity with impressive TONs of up to $3.5 \times 10^{6} .^{13-20}$ However, important progress could also be achieved with the development of molecular catalysts based on nonprecious metals. In 2003, the Jessop group screened a series of metal salts and found the catalyst $\mathrm{NiCl}_{2} / \mathrm{dcpe}\left(\mathrm{dcpe}=\mathrm{Cy}_{2} \mathrm{PCH}_{2} \mathrm{CH}_{2}\right.$ $\mathrm{PCy}_{2}$ ) with the base DBU (DBU $=1,8$-diazabicycloundec-7-ene)

Institut für Makromolekulare und Technische Chemie, RWTH Aachen University, Worringerweg 2, 52074 Aachen, Germany. E-mail: jklankermayer@itmc. rwth-aachen.de

$\dagger$ Electronic supplementary information (ESI) available. See DOI: 10.1039/c8sc05230a as an effective system, resulting in a TON of 4400 after 216 hours at $50{ }^{\circ} \mathrm{C} .{ }^{21}$ The Beller group developed Fe and Co catalysts with a tetradentate ligand and in their experiments a TON of up to $1300(\mathrm{M}=\mathrm{Co})$ could be achieved in the hydrogenation of $\mathrm{CO}_{2}$ to dimethyl formamide (DMF). ${ }^{22,23}$ An improved iron system, developed by the same group, based on another tetradentate ligand resulted in an even higher TON of 5100 for DMF. ${ }^{24}$ Linehan and co-workers presented a remarkable active in situ cobalt system with a bidentate ligand (dmpe $=1,2$-bis(dimethylphosphino)ethane) in combination with Verkade's base, resulting in TOFs of up to $74000 \mathrm{~h}^{-1}$ and TONs of up to 9400 at room temperature. ${ }^{25}$ Furthermore, the Linehan group reported of two nickel catalyst systems capable of hydrogenating $\mathrm{CO}_{2}$. The first system showed feasibility of $\mathrm{CO}_{2}$ hydrogenation in water with a homogeneous nickel catalyst. ${ }^{26}$ Recently, another reported catalyst achieved high TONs for $\mathrm{CO}_{2}$ hydrogenation, again relying on the strong Verkade's base. A bimetallic nickelgallium catalyst was able to perform the reaction at room temperature with TONs of up to 3150 (Fig. 1). ${ }^{27}$

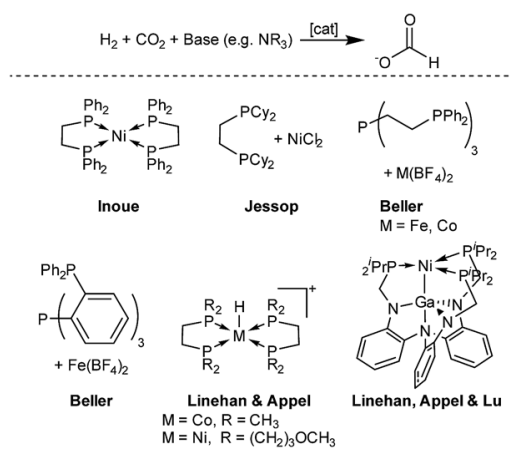

Fig. 1 Selected non-precious metal catalysts for the hydrogenation of $\mathrm{CO}_{2}$ to formate. .1,22-27 $^{2}$ 
In summary, the use of first row transition metals has already been demonstrated, but the achieved TON and TOF values are typically one or two orders of magnitude below those of the best platinum group systems, and highly active and effective systems with non-precious transition metals remain largely elusive. ${ }^{28,29}$ Based on the important results achieved with molecular nickel-based catalysts, improved catalyst performance was envisaged with a tailored multidentate ligand structure.

In the first set of $\mathrm{CO}_{2}$ hydrogenation experiments a screening of carefully chosen multidentate ligands in combination with $\mathrm{Ni}\left(\mathrm{BF}_{4}\right)_{2}$ and DBU as the base was performed (Scheme 1).

Selected results of this initial investigation are summarized in Table 1. In the first experiment with the bidentate phosphine ligand dmpe (1,2-bis(dimethylphosphanyl)ethane) and $\mathrm{Ni}\left(\mathrm{BF}_{4}\right)_{2}$ a low TON of 36 could be obtained (Table 1, entry 1). Using the tridentate ligand triphos (1,1,1-tris(diphenylphosphinomethyl) ethane) an increased TON of 79 was achieved and with the related $\quad N$-triphos ( $N, N, N$-tris((diphenylphosphanyl)methyl) amine) a higher TON of 184 was obtained (Table 1, entry 2 and $3)$. The remarkable difference between these two ligands suggests the importance of an additional coordination site with nickel based molecular systems. However, applying ligands with an additional Lewis basic center and a more flexible ligand backbone showed only a very low catalytic activity. In detail, the reaction with the TPA-based catalyst (TPA = trispyridylmethylamine) resulted in a TON of 14 and with $\mathrm{PP}_{3}$ (tris(2-(diphenylphosphino)ethyl)phosphine) a TON of only 41 could be achieved (Table 1, entry 4 and 5).

Remarkably, using the tetradentate ligand $\mathrm{NP}_{3}\left(\mathrm{NP}_{3}=\operatorname{tris}(2-\right.$ (diphenylphosphino)ethyl)amine) showed a high productivity with a TON of 846 (Table 1, entry 6). Using the sterically more strained equivalent $\mathrm{NP}_{3}{ }^{\mathrm{Cy}}\left(\mathrm{NP}_{3}{ }^{\mathrm{Cy}}=\operatorname{tris}(2\right.$-(dicyclohexylphosphino)ethyl)amine) a decreased turnover number of 384 was obtained (Table 1, entry 7). Based on these results, the $\mathrm{NP}_{3}$ ligand showed an excellent performance, and the interplay of the bridgehead nitrogen atom with the nickel center has exceptional importance in the catalyst activity. Recently published results by Mondal et al. calculating the energy profile of molecular cobalt and iron catalysts bearing a tetradentate ligand with varying bridgehead atoms corroborate this conclusion. ${ }^{30}$

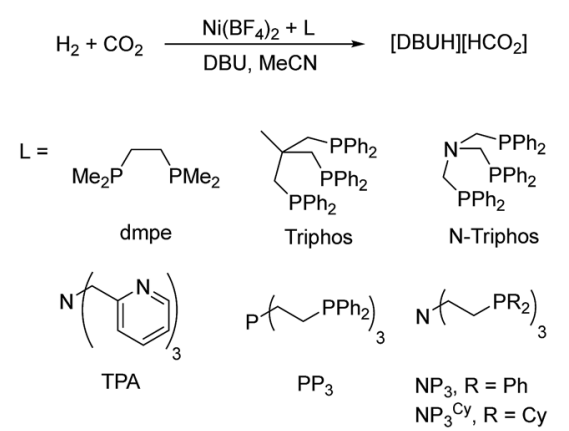

Scheme 1 Nickel-catalyzed hydrogenation of $\mathrm{CO}_{2}$ with selected multidentate ligands.
Table 1 Screening of various ligands for the reduction of $\mathrm{CO}_{2}$ with $\mathrm{Ni}^{a}$

\begin{tabular}{llll}
\hline Entry & Ligand & TON $^{b}$ & Yield [\%] \\
\hline $1^{c}$ & dmpe & 36 & 3.6 \\
2 & triphos & 79 & 8 \\
3 & $N$-triphos & 184 & 18 \\
4 & $\mathrm{TPA}$ & 14 & 1.4 \\
5 & $\mathrm{PP}_{3}$ & 41 & 4 \\
6 & $\mathrm{NP}_{3}$ & 846 & 85 \\
7 & $\mathrm{NP}_{3}{ }^{\mathrm{Cy}}$ & 384 & 38
\end{tabular}

${ }^{a} \mathrm{Ni}\left(\mathrm{BF}_{4}\right)_{2} \cdot 6 \mathrm{H}_{2} \mathrm{O}(5 \mu \mathrm{mol}), 1$ eq. of ligand, $n_{\mathrm{DBU}}=5 \mathrm{mmol}$ (1000 eq.), $V_{\mathrm{MeCN}}=2 \mathrm{~mL}, T=100{ }^{\circ} \mathrm{C}, t=20 \mathrm{~h}, p\left(\mathrm{H}_{2} / \mathrm{CO}_{2}\right)[\mathrm{bar} / \mathrm{bar}]=60 / 30$ at $\mathrm{r}$. t. ${ }^{b}$ TON $=n_{\text {formate }} / n_{\text {cat }}$ based on integration of the ${ }^{1} \mathrm{H}-\mathrm{NMR}$ resonances of $[\mathrm{DBUH}]\left[\mathrm{HCO}_{2}\right]$ with mesitylene as the internal standard. ${ }^{c} 2$ eq. of ligand used.

Consequently, further investigations focused on the application of the versatile $\mathrm{NP}_{3}$ ligand in combination with $\mathrm{Ni}\left(\mathrm{BF}_{4}\right)_{2}$.

In the first set of experiments, variation of temperature between 80 and $140{ }^{\circ} \mathrm{C}$ revealed $120^{\circ} \mathrm{C}$ as the optimal reaction temperature. In detail, at $80^{\circ} \mathrm{C}$ a TON of 650 was achieved after $20 \mathrm{~h}$, which corresponds to an acid-to-amine-ratio (AAR = $n_{\text {formate }} / n_{\mathrm{DBU}}$ ) of approximately 0.33 (Table 2 , entry 1 ). This ratio could be further increased to 0.43 at a temperature of $100{ }^{\circ} \mathrm{C}$ (Table 2, entry 2). A nearly full conversion of DBU with a higher AAR of 0.99 was accomplished at $120^{\circ} \mathrm{C}$, resulting in a TON of 1970 (Table 2 , entry 3 ). The reaction at $140{ }^{\circ} \mathrm{C}$ led to a significantly increased TON of 1250 after $20 \mathrm{~h}$, but to a maximum AAR of only 0.65 as well due to reduced catalyst stability under these extreme conditions (Table 2, entry 4 ).

Table 2 Hydrogenation of $\mathrm{CO}_{2}$ with the developed $\mathrm{Ni}\left(\mathrm{BF}_{4}\right)_{2} / \mathrm{NP}_{3}$ system $^{a}$

\begin{tabular}{llllll}
\hline & $\begin{array}{l}n\left(\mathrm{Ni}\left(\mathrm{BF}_{4}\right)_{2}\right) \\
{[\mu \mathrm{mol}]}\end{array}$ & $T\left[{ }^{\circ} \mathrm{C}\right]$ & $\mathrm{TON}^{b}$ & $\mathrm{TOF}_{\text {avg }}{ }^{c}\left[\mathrm{~h}^{-1}\right]$ & $\mathrm{AAR}^{d}$ \\
\hline 1 & 5.0 & 80 & 650 & 33 & 0.33 \\
2 & 5.0 & 100 & 850 & 43 & 0.43 \\
3 & 5.0 & 120 & 1970 & 99 & 0.99 \\
4 & 5.0 & 140 & 1250 & 52 & 0.65 \\
5 & 0.5 & 120 & 20900 & 290 & 1.05 \\
6 & 0.2 & 120 & 54219 & 753 & 1.08 \\
7 & 0.1 & 120 & 93270 & 1336 & 0.93 \\
8 & 0.04 & 120 & 226630 & 3148 & 0.91 \\
9 & 0.02 & 120 & 444610 & 6175 & 0.89 \\
10 & 0.002 & 120 & 4650710 & 64593 & 0.93 \\
$11^{e}$ & 5.0 & 120 & 0 & - & - \\
$12^{f}$ & 5.0 & 120 & 30 & 0.4 & 0.02 \\
$13^{g}$ & - & 120 & 0 & - & - \\
$14^{h}$ & 5.0 & 120 & 548 & 27 & 0.27 \\
$15^{i}$ & 5.0 & 120 & 653 & 32 & 0.32 \\
$16^{j}$ & 5.0 & 120 & 37 & 2 & 0.01
\end{tabular}

${ }^{a} \mathrm{Ni}\left(\mathrm{BF}_{4}\right)_{2} \cdot 6 \mathrm{H}_{2} \mathrm{O}, 1$ eq. of $\mathrm{NP}_{3}, V_{\mathrm{MeCN}}=2 \mathrm{~mL}, n_{\mathrm{DBU}}=10 \mathrm{mmol}$ (2000 eq.), $p\left(\mathrm{H}_{2} / \mathrm{CO}_{2}\right)[\mathrm{bar} / \mathrm{bar}]=60 / 30$ at r. t., entries 1-4, 14-16: $t=20 \mathrm{~h}$, entries 5-13: $t=72$ h. ${ }^{b}$ TON $=n_{\text {formate }} / n_{\text {cat }}$ based on integration of the ${ }^{1} \mathrm{H}$-NMR resonances of $[\mathrm{DBUH}]\left[\mathrm{HCO}_{2}\right]$ with mesitylene as the internal standard. ${ }^{c}$ Given as average TOF, $\mathrm{TOF}_{\mathrm{avg}}=\mathrm{TON} / t$ over the whole reaction period. ${ }^{d} \mathrm{AAR}=n_{\text {formate }} / n_{\mathrm{DBU}} \cdot{ }^{e}$ Without DBU. ${ }^{f}$ Without $\mathrm{NP}_{3} \cdot{ }^{g} n_{\mathrm{NP}_{3}}=5 \mu \mathrm{mol} .{ }^{h}$ 5 eq. of $\mathrm{PCy}_{3} .{ }^{i}$ One additional eq. of $\mathrm{NP}_{3} .{ }^{j} 1100$ eq. of $\mathrm{H}_{2} \mathrm{O}(0.1 \mathrm{~mL}, 5.5$ mmol) added. 
In the next set of experiments, the catalyst loading was systematically reduced and correlated to the respective TONs (Table 2, entries 5-9). Decreasing the catalyst loading resulted in an increased TON and with $0.002 \mu \mathrm{mol}$ nickel catalyst an outstanding TON of approximately $4.65 \times 10^{6}$ could be achieved (Table 2, entry 10), surpassing that of established systems based on first row transition metals and even systems based on precious metals.

Control experiments revealed the tailored combination of $\mathrm{Ni}\left(\mathrm{BF}_{4}\right)_{2}, \mathrm{NP}_{3}$ ligand and $\mathrm{DBU}$ as the basic requirement for the exceptionally high activity (Table 2, entries 11-13). Recently, Zall et al. observed the coordination of the DBU base to the metal center as a crucial factor for a high catalytic turnover in the hydrogenation of $\mathrm{CO}_{2}$ with copper catalysts and a comparable pathway may thus be present in the established $\mathrm{NP}_{3} / \mathrm{Ni}$ / DBU system. ${ }^{29}$ Thus, to gain further insight into the complex reaction mechanism, experiments with a defined organometallic compound were performed. Using the molecular nickel(0) complex $\mathrm{NP}_{3} \mathrm{Ni}^{31}$ comparable results and a TON of 2180 could be obtained, thus corroborating the formation of a molecular species during the in situ procedure. Furthermore, a mercurypoisoning test showed no inhibition of the catalytic activity. Additionally, an excess of phosphine ligands such as tricyclohexylphosphine $\left(\mathrm{PCy}_{3}\right)$ to a $1: 1$ mixture of $\mathrm{Ni}^{2+} / \mathrm{NP}_{3}$ resulted in a highly decreased TON and a low AAR (Table 2, entry 14). Even the addition of just one additional equivalent of $\mathrm{NP}_{3}$ results in reduced activity and a low TON/AAR (Table 2, entry 15). High amounts of water hinder the catalytic hydrogenation of $\mathrm{CO}_{2}$. The addition of approx. 1000 equivalents of water leads to inhibition of catalysis (Table 2, entry 16) and the formation of a precipitate. The exact molecular structure of the catalyst remains currently unknown. However, further spectroscopic experiments and mass analysis showed the formation of multiple compounds possibly active in the $\mathrm{CO}_{2}$ hydrogenation (see the ESI $\dagger$ for further explanation).

A sequential reaction set-up of subsequently refilling the autoclave with DBU as well as $\mathrm{CO}_{2}$ and molecular hydrogen leads to outstanding synthesis of the respective formate on a multigram scale (Scheme 2).

Analysis of the reaction mixture after a course of five reactions showed quantitative conversion of the free base resulting in a good TON of $6324(\mathrm{AAR}=1.05)$. This productivity denotes an overall yield of roughly $6.30 \mathrm{~g}(31.62 \mathrm{mmol})$ of isolable [DBUH] formate and further shows the stability of the nickel catalyst system in this study.

Towards the development of a more effective system and inspired by recent results, ${ }^{32-35}$ selected Lewis acidic additives were investigated in combination with the nickel $\mathrm{NP}_{3}$ system (Table 3).

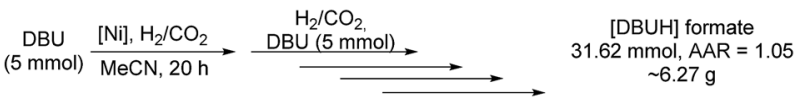

Scheme 2 Sequential hydrogenation of $\mathrm{CO}_{2}$ by the established nickel catalyst system. $10 \mathrm{mmol}$ of DBU instead of $5 \mathrm{mmol}$ was added in the last reaction step.
Table 3 Hydrogenation of $\mathrm{CO}_{2}$ with the developed $\mathrm{Ni}^{2+} / \mathrm{NP}_{3}$ system in the presence of selected Lewis acidic additives ${ }^{a}$

\begin{tabular}{lllll}
\hline Entry & Lewis acid (LA) & TON $^{b}$ & TOF $_{\text {avg }}^{c}\left[\mathrm{~h}^{-1}\right]$ & $\mathrm{AAR}^{d}$ \\
\hline 1 & - & 1545 & 77 & 0.31 \\
2 & $\mathrm{~B}\left(\mathrm{C}_{6} \mathrm{~F}_{5}\right)_{3}$ & 1560 & 78 & 0.31 \\
3 & $\mathrm{Zn}(\mathrm{OTf})_{2}$ & 1707 & 85 & 0.34 \\
4 & $\mathrm{Al}(\mathrm{OTf})_{3}$ & 130 & 7 & 0.03 \\
5 & $\mathrm{LiBF}_{4}$ & 5440 & 272 & 1.09 \\
6 & $\mathrm{LiI}$ & 4590 & 230 & 0.97 \\
7 & $\mathrm{LiCl}$ & 5140 & 260 & 1.08 \\
8 & $\mathrm{NaBF}_{4}$ & 400 & 20 & 0.09 \\
$9^{e}$ & $\mathrm{LiBF}_{4}$ & 6260 & 313 & 0.63
\end{tabular}

${ }^{a} \mathrm{Ni}\left(\mathrm{BF}_{4}\right)_{2} \cdot 6 \mathrm{H}_{2} \mathrm{O}(2 \mu \mathrm{mol})$ and 1 eq. of $\mathrm{NP}_{3}$ used, $n_{\mathrm{LA}}=200 \mu \mathrm{mol}, n_{\mathrm{DBU}}=$ $10 \mathrm{mmol}$ (5000 eq.), $V_{\mathrm{MeCN}}=2 \mathrm{~mL}, p\left(\mathrm{H}_{2} / \mathrm{CO}_{2}\right)[\mathrm{bar} / \mathrm{bar}]=60 / 30$ at r. t., $T$ $=120{ }^{\circ} \mathrm{C}, t=20 \mathrm{~h} .{ }^{b}$ TON $=n_{\text {formate }} / n_{\text {cat }}$ based on integration of the ${ }^{1} \mathrm{H}-$ NMR resonances of $[\mathrm{DBUH}]\left[\mathrm{HCO}_{2}\right]$ with mesitylene as the internal standard. ${ }^{c}$ Given as average TOF, $\mathrm{TOF}_{\mathrm{avg}}=\mathrm{TON} / t$ over the whole reaction period. ${ }^{d} \mathrm{AAR}=n_{\text {formate }} / n_{\mathrm{DBU}} \cdot{ }^{e} n_{\mathrm{Ni}}=1 \mu \mathrm{mol}$.

Without any additive, after $20 \mathrm{~h}$ a TON of approximately 1500 could be obtained (Table 3 , entry 1 ). Lewis acids such as tris(pentafluorophenyl)borane $\left(\mathrm{B}\left(\mathrm{C}_{6} \mathrm{~F}_{5}\right)_{3}\right)$ or zinc triflate $\left(\mathrm{Zn}(\mathrm{OTf})_{2}\right)$ did not enhance the activity of the established system (Table 3 , entries 2 and 3 ). Aluminium triflate (Al(OTf $)_{3}$ ) inhibits catalysis and nearly no formate could be observed (Table 3, entry 4). Using lithium tetrafluoroborate $\left(\mathrm{LiBF}_{4}\right)$ a clear enhancement in the catalytic activity was seen achieving a TON of up to 5440 and an AAR of 1.09 (Table 3, entry 5). The tested lithium halides, lithium iodide (LiI) and lithium chloride ( $\mathrm{LiCl}$ ), exhibited a similar behavior in catalysis leading to only slightly decreased values of TONs and AARs (Table 3, entries 5 and 6). Switching from lithium to sodium tetrafluoroborate $\left(\mathrm{NaBF}_{4}\right)$ has a clearly inhibiting effect resulting in only a poor yield of formate in a TON of 400 (Table 3, entry 8). By using $\mathrm{LiBF}_{4}$ and additionally lowering the catalyst amount, an AAR of only 0.63 after $20 \mathrm{~h}$ with an excellent TON of 6260 could be achieved. Consequently, longer reaction times are required to obtain full conversion of the amine substrate (Table 3, entry 9). To gain further insights into the molecular species formed during catalysis, detailed NMR spectroscopic and mass spectrometric experiments were performed. In detail, ${ }^{31} \mathrm{P}-\mathrm{NMR}$-spectroscopy revealed the sole formation of a $\mathrm{NP}_{3} /$ $\mathrm{Ni}^{2+}$ complex by mixing the ligand and $\mathrm{Ni}\left(\mathrm{BF}_{4}\right)_{2}$. Analysis after the catalytic experiment revealed a reduction of the initially formed $\mathrm{NP}_{3} \mathrm{Ni}$ (II) complex, leading to the formation of a major species with a chemical shift of $21 \mathrm{ppm}$. Confirmation of the defined species $\mathrm{NP}_{3} \mathrm{Ni}(0)$ could be obtained with a further control experiment. Consequently, a mixture of $\mathrm{NP}_{3} / \mathrm{Ni}^{2+}, \mathrm{DBU}$ and molecular hydrogen ( $p=3$ bar) resulted in a ${ }^{31} \mathrm{P}-\mathrm{NMR}$ spectrum comparable to that of a post-reaction mixture (for details see the ESI $\dagger$ ). However, the isolated $\mathrm{NP}_{3} \mathrm{Ni}$ complex did not show evidence of distinct reactivity towards molecular hydrogen and even after prolonged heating at $80{ }^{\circ} \mathrm{C}$, no formation of a hydride species could be observed by NMR spectroscopy. Additional HR ESI-MS measurements confirmed the formation of a $\mathrm{NP}_{3} \mathrm{Ni}^{2+}$ species from the $\mathrm{NP}_{3} / \mathrm{Ni}^{2+}$ mixture during the catalytic experiment (see the $\mathrm{ESI}_{\dagger} \dagger$ ). 


\section{Conclusions}

In conclusion, a non-precious transition metal catalyst system could be developed for homogeneous hydrogenation of $\mathrm{CO}_{2}$ to formate. The application of the versatile multidentate $\mathrm{NP}_{3}$ ligand in combination with selected nickel(II) salts enabled the effective transformation of $\mathrm{CO}_{2}$ in the presence of molecular hydrogen in acetonitrile solution. Under optimized conditions, using $0.002 \mu \mathrm{mol}$ nickel catalyst, an exceptional TON of approximately $4.65 \times 10^{6}$ was achieved. This unprecedented productivity based on the novel nickel catalyst not only outmatches that of existing systems containing first row transition metals, but also established catalysts based on precious transition metals. Further development and detailed mechanistic investigations on the catalyst system are ongoing in our laboratories.

\section{Experimental section}

The general procedure for homogeneous hydrogenation of carbon dioxide to formate using $\mathrm{Ni}\left(\mathrm{BF}_{4}\right)_{2} \cdot 6 \mathrm{H}_{2} \mathrm{O}$ and $\mathrm{NP}_{3}$ : under an argon atmosphere, a Schlenk tube was charged with a freshly prepared stock solution $\left(c_{\mathrm{Ni} / \mathrm{NP}_{3}}=2.5 \mu \mathrm{mol} \mathrm{mL}{ }^{-1}\right)$ of $\mathrm{Ni}\left(\mathrm{BF}_{4}\right)_{2} \cdot 6 \mathrm{H}_{2} \mathrm{O}$ and $\mathrm{NP}_{3}$. In the case of highly diluted reactions the stock solution was further diluted (see the ESI $\dagger$ for detailed information). DBU was added and the solution was transferred to a stainless steel autoclave equipped with a glass inlet under argon. The autoclave was pressurized with $\mathrm{CO}_{2}$ (30 bar) until saturation, followed by hydrogen to a total pressure of 90 bar at room temperature. The reaction mixture was stirred and heated to the respective reaction temperature in an aluminium heating cone. After the reaction period, the autoclave was cooled to room temperature and then carefully vented. Mesitylene was added as the internal standard and the resulting solution was analysed by ${ }^{1} \mathrm{H}$-NMR-spectroscopy. The TONs were found to be reproducible within $\Delta \mathrm{TON}= \pm 10 \%$ in at least two independent runs in selected experiments.

\section{Conflicts of interest}

There are no conflicts to declare.

\section{Acknowledgements}

This work was supported in part by the Deutsche Forschungsgemeinschaft (DFG, German Research Foundation) under Germany's Excellence Strategy - Exzellenzcluster 2186 “The Fuel Science Center" ID: 390919832, and by the German Federal Ministry of Education and Research (BMBF) within the Kopernikus Project P2X: Flexible use of renewable resources exploration, validation and implementation of 'Power-to- $\mathrm{X}$ ' concepts.

\section{Notes and references}

1 W.-H. Wang, Y. Himeda, J. T. Muckerman, G. F. Manbeck and E. Fujita, Chem. Rev., 2015, 115, 12936-12973.
2 J. Klankermayer, S. Wesselbaum, K. Beydoun and W. Leitner, Angew. Chem., Int. Ed., 2016, 55, 7296-7343.

3 J. Klankermayer and W. Leitner, Science, 2015, 350, 629-630.

4 S. Moret, P. J. Dyson and G. Laurenczy, Nat. Commun., 2014, 5, 4017-4023.

5 S. Wesselbaum, T. vom Stein, J. Klankermayer and W. Leitner, Angew. Chem., Int. Ed., 2012, 124, 7499-7502.

6 N. M. Rezayee, C. A. Huff and M. S. Sanford, J. Am. Chem. Soc., 2015, 137, 1028-1031.

7 C. A. Huff and M. S. Sanford, J. Am. Chem. Soc., 2011, 133, 18122-18125.

8 K. Thenert, K. Beydoun, J. Wiesenthal, W. Leitner and J. Klankermayer, Angew. Chem., Int. Ed., 2016, 55, 1226612269.

9 B. G. Schieweck and J. Klankermayer, Angew. Chem., Int. Ed., 2017, 56, 10854-10857.

10 M. W. Farlow and H. Adkins, J. Am. Chem. Soc., 1935, 57, 2222-2223.

11 Y. Inoue, H. Izumida, Y. Sasaki and H. Hashimoto, Chem. Lett., 1976, 5, 863-864.

12 K. Rohmann, J. Kothe, M. W. Haenel, U. Englert, M. Hölscher and W. Leitner, Angew. Chem., Int. Ed., 2016, 55, 8966-8969.

13 R. Tanaka, M. Yamashita and K. Nozaki, J. Am. Chem. Soc., 2009, 131, 14168-14169.

14 G. A. Filonenko, R. van Putten, E. N. Schulpen, E. J. M. Hensen and E. A. Pidko, ChemCatChem, 2014, 6, 1526-1530.

15 S. Wesselbaum, U. Hintermair and W. Leitner, Angew. Chem., Int. Ed., 2012, 51, 8585-8588.

16 A. Boddien, C. Federsel, P. Sponholz, D. Mellmann, R. Jackstell, H. Junge, G. Laurenczy and M. Beller, Energy Environ. Sci., 2012, 5, 8907-8911.

17 W. Leitner, E. Dinjus and F. Gaßner, J. Organomet. Chem., 1994, 475, 257-266.

18 W. Leitner, Angew. Chem., Int. Ed., 1995, 34, 2207-2221.

19 P. G. Jessop, T. Ikariya and R. Noyori, Nature, 1994, 368, 231233.

20 P. Munshi, A. D. Main, J. C. Linehan, C.-C. Tai and P. G. Jessop, J. Am. Chem. Soc., 2002, 124, 7963-7971.

21 C.-C. Tai, T. Chang, B. Roller and P. G. Jessop, Inorg. Chem., 2003, 42, 7340-7341.

22 C. Federsel, C. Ziebart, R. Jackstell, W. Baumann and M. Beller, Chem.-Eur. J., 2012, 18, 72-75.

23 C. Federsel, A. Boddien, R. Jackstell, R. Jennerjahn, P. J. Dyson, R. Scopelliti, G. Laurenczy and M. Beller, Angew. Chem., Int. Ed., 2010, 49, 9777-9780.

24 C. Ziebart, C. Federsel, P. Anbarasan, R. Jackstell, W. Baumann, A. Spannenberg and M. Beller, J. Am. Chem. Soc., 2012, 134, 20701-20704.

25 M. S. Jeletic, M. T. Mock, A. M. Appel and J. C. Linehan, J. Am. Chem. Soc., 2013, 135, 11533-11536.

26 S. A. Burgess, A. J. Kendall, D. R. Tyler, J. C. Linehan and A. M. Appel, ACS Catal., 2017, 7, 3089-3096.

27 R. C. Cammarota, M. V. Vollmer, J. Xie, J. Ye, J. C. Linehan, S. A. Burgess, A. M. Appel, L. Gagliardi and C. C. Lu, J. Am. Chem. Soc., 2017, 139, 14244-14250. 
28 Y. M. Badiei, W.-H. Wang, J. F. Hull, D. J. Szalda, J. T. Muckerman, Y. Himeda and E. Fujita, Inorg. Chem., 2013, 52, 12576-12586.

29 C. M. Zall, J. C. Linehan and A. M. Appel, ACS Catal., 2015, 5, 5301-5305.

30 B. Mondal, F. Neese and S. Ye, Inorg. Chem., 2016, 55, 54385444.

31 L. Sacconi, C. A. Ghilardi, C. Mealli and F. Zanobini, Inorg. Chem., 1975, 14, 1380-1386.
32 E. A. Bielinski, P. O. Lagaditis, Y. Zhang, B. Q. Mercado, C. Würtele, W. H. Bernskoetter, N. Hazari and S. Schneider, J. Am. Chem. Soc., 2014, 136, 10234-10237.

33 Y. Zhang, A. D. MacIntosh, J. L. Wong, E. A. Bielinski, P. G. Williard, B. Q. Mercado, N. Hazari and W. H. Bernskoetter, Chem. Sci., 2015, 6, 4291-4299.

34 A. Z. Spentzos, C. L. Barnes and W. H. Bernskoetter, Inorg. Chem., 2016, 55, 8225-8233.

35 F. Bertini, M. Glatz, N. Gorgas, B. Stoger, M. Peruzzini, L. F. Veiros, K. Kirchner and L. Gonsalvi, Chem. Sci., 2017, 8, 5024-5029. 